\title{
A noteworthy range extension for Haradaea moenchiae- manticae, a rarely reported smut fungus
}

\section{Teodor T. Denchev \& Cvetomir M. Denchev*}

Institute of Biodiversity and Ecosystem Research, Bulgarian Academy of Sciences, 2 Gagarin St., 1113 Sofia, Bulgaria

Received 10 April 2017 / Accepted 13 April 2017 / Published 26 April 2017

Denchev, T.T. \& Denchev, C.M. 2017. A noteworthy range extension for Haradaea moenchiae-manticae, a rarely reported smut fungus. - Mycobiota 7: 7-12. doi: 10.12664/mycobiota.2017.07.02

Abstract. Haradaea moenchiae-manticae is reported for the first time from the Iberian Peninsula (from Spain), on Moenchia erecta subsp. erecta, and from Africa (from Morocco and Algeria), on a new host plant, M. erecta subsp. octandra.

Key words: Africa, Algeria, Haradaea moenchiae-manticae, Iberian Peninsula, Microbotryaceae, Moenchia, Morocco, smut fungi, Spain, taxonomy

\section{Introduction}

The genus Haradaea was described for accommodation of a group of former Ustilago species on caryophyllaceous plants that destroy ovules, filling the capsules with purplish spore mass (Denchev et al. 2006b). Haradaea comprises nine species (Denchev 2006; Denchev et al. $2006 \mathrm{a}, \mathrm{b})$.

Haradaea moenchiae-manticae is a rarely collected smut fungus on plants in the genus Moenchia, currently known from Serbia, Romania, Bulgaria, and UK (Lindtner 1950; Săvulescu 1957; Vánky 1985, 2011; Denchev 1997, 2001; Denchev et al. 2010). It is reported here as a new species for the Iberian Peninsula and Africa (cf. Almaraz 2002; Vánky et al. 2011), based on specimens observed in the herbarium and mycological collection of the Royal Botanic Garden, Madrid (MA) in April 2017.

\footnotetext{
*Corresponding author: e-mail: cmdenchev@yahoo.co.uk
} 


\section{Material and methods}

Dried specimens from the herbarium and mycological collection of the Royal Botanic Garden, Madrid (MA) were examined with a light microscope (LM) and scanning electron microscope (SEM). For LM observations and measurements, spores were mounted in lactoglycerol solution ( $\mathrm{w}: \mathrm{la}: \mathrm{gl}=1: 1: 2$ ) on glass slides, gently heated to boiling point to rehydrate the spores, and then cooled. The measurements of spores are given in the form: min-max (extreme values) (mean \pm 1 standard deviation). The total number of spores ( $\mathrm{n}$ ) from all collections $(\mathrm{x})$ measured are given in the form ' $(\mathrm{n} / \mathrm{x})$ '. For SEM, spores were attached to specimen holders by double-sided adhesive tape and coated with gold in an ion sputter. The surface structure of spores was observed and photographed at $10 \mathrm{kV}$ accelerating voltage using a Hitachi S-3000N scanning electron microscope. The description given below is based entirely on the specimens examined.

\section{Taxonomy}

Haradaea moenchiae-manticae (Lindtner) Denchev \& H.D. Shin, in Denchev et al., Mycologia Balcanica 3: 72, 2006.

Figs 1-8

E Ustilago moenchiae-manticae Lindtner, Bulletin du Muséum d'Histoire Naturelle du Pays Serbe, Série B 3-4: 32, 1950.

三 Microbotryum moenchiae-manticae (Lindtner) Vánky, Mycotaxon 67: 46, 1998.

Sori destroying the ovules and filling the capsules with a semi-agglutinated, at maturity pulverulent, purplish brown spore mass. Spores subglobose, globose or broadly ellipsoidal, sometimes ovoid, (11.5-)12-15.5(-17) × (10.5-) 11-14.5(-15.5) (13.7 $\pm 0.8 \times 12.6 \pm 0.8)$ $\mu \mathrm{m}(\mathrm{n} / 3=300)$, medium purplish brown; wall $1.7-2.3 \mu \mathrm{m}$ thick (including reticulum), reticulate, meshes 5-8(-9) per spore diameter, polyhedral or irregular, 1.0-2.8(-3.3) $\mu \mathrm{m}$ wide, muri (0.8-)1.0-1.4(-1.7) $\mu \mathrm{m}$ high; in SEM the meshes often with a hemispherical protuberance on the bottom.

Specimens examined - On Moenchia erecta (L.) P. Gaertn. et al. subsp. erecta: SPAIN, SALAMANCA, Martiago, 25 April 1976, leg. E. Rico, s.n. (MA 205833). - On M. erecta subsp. octandra (Ziz ex Mert. \& W.D.J. Koch) Gürke ex Cout.: MOROCCO, Dj. BouZabel, 1300 m, 3 May 1933, leg. A. Faure, s.n. (MA 35045); ALGERIA, TIZI OUZOU PROVINCE, Fort National (currently, Larbaâ Nath Irathen), 28 April 1915, leg. L. Ducellier, no. 2433 (MA-Funhist 17169; distributed in R. Maire, Mycotheca BorealiAfricana, no. 203, as Ustilago duriaeana Tul. \& C. Tul. on Cerastium glaucum var. octandrum (Salzm. ex Reichenb.) Gren.; see Maire 1916: 298-299).

Distribution - On Caryophyllaceae: Moenchia erecta subsp. erecta (Bulgaria, Spain, and UK), M. erecta subsp. octandra (Algeria and Morocco), and M. mantica (L.) Bartl. subsp. mantica (Romania and Serbia); Europe and North Africa (Fig. 9).

Moenchia erecta subsp. octandra is a new host plant record for Haradaea moenchiaemanticae. 


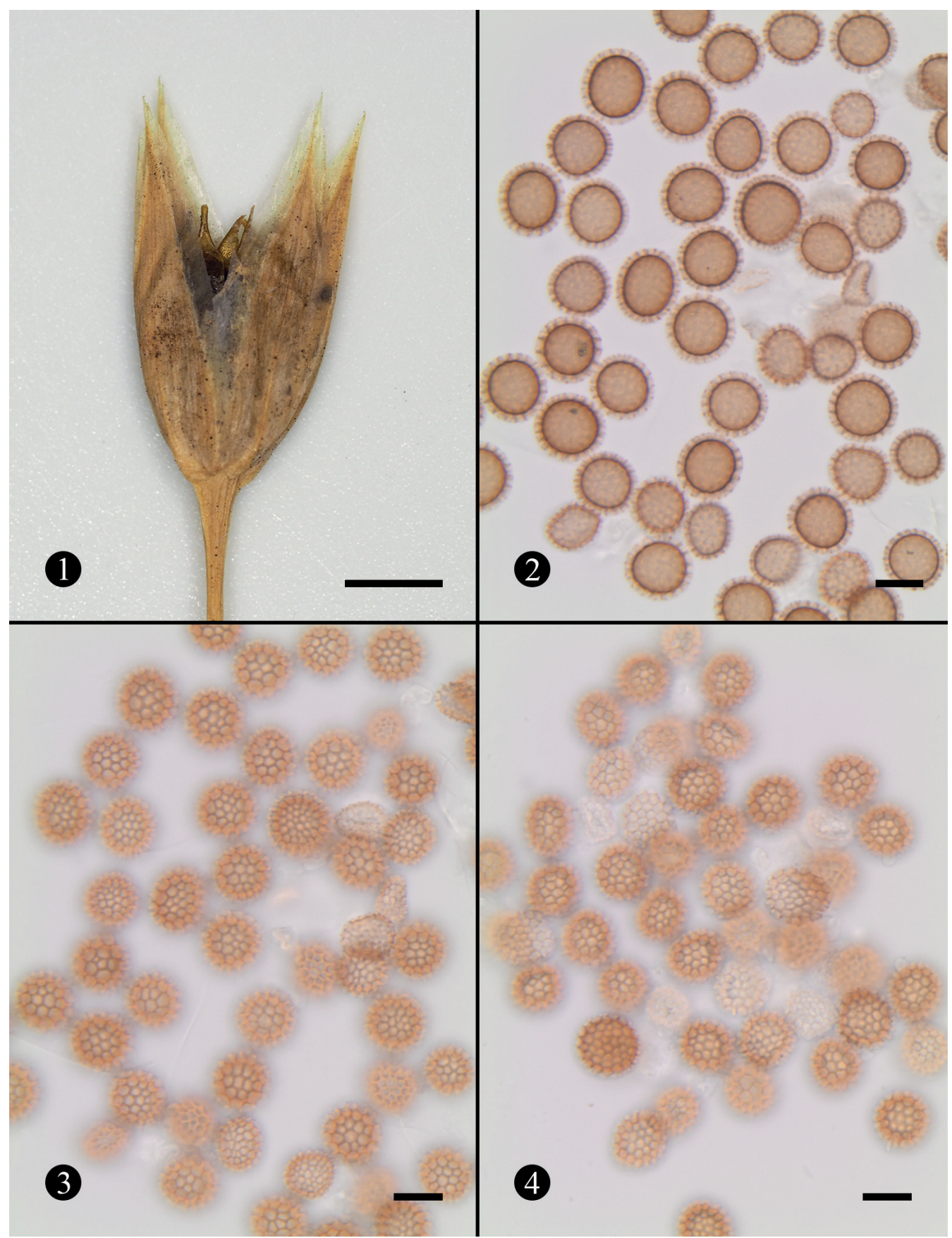

Figs 1-3. Haradaea moenchiae-manticae on Moenchia erecta subsp. octandra (MA 35045). 1. Habit. 2, 3. Spores in LM (in median and surface view, respectively). Fig. 4. Spores of $H$. moenchiae-manticae on Moenchia erecta subsp. erecta (MA 205833) in LM (in surface view). Scale bars: $1=2 \mathrm{~mm}, 2-4=10 \mu \mathrm{m}$ 


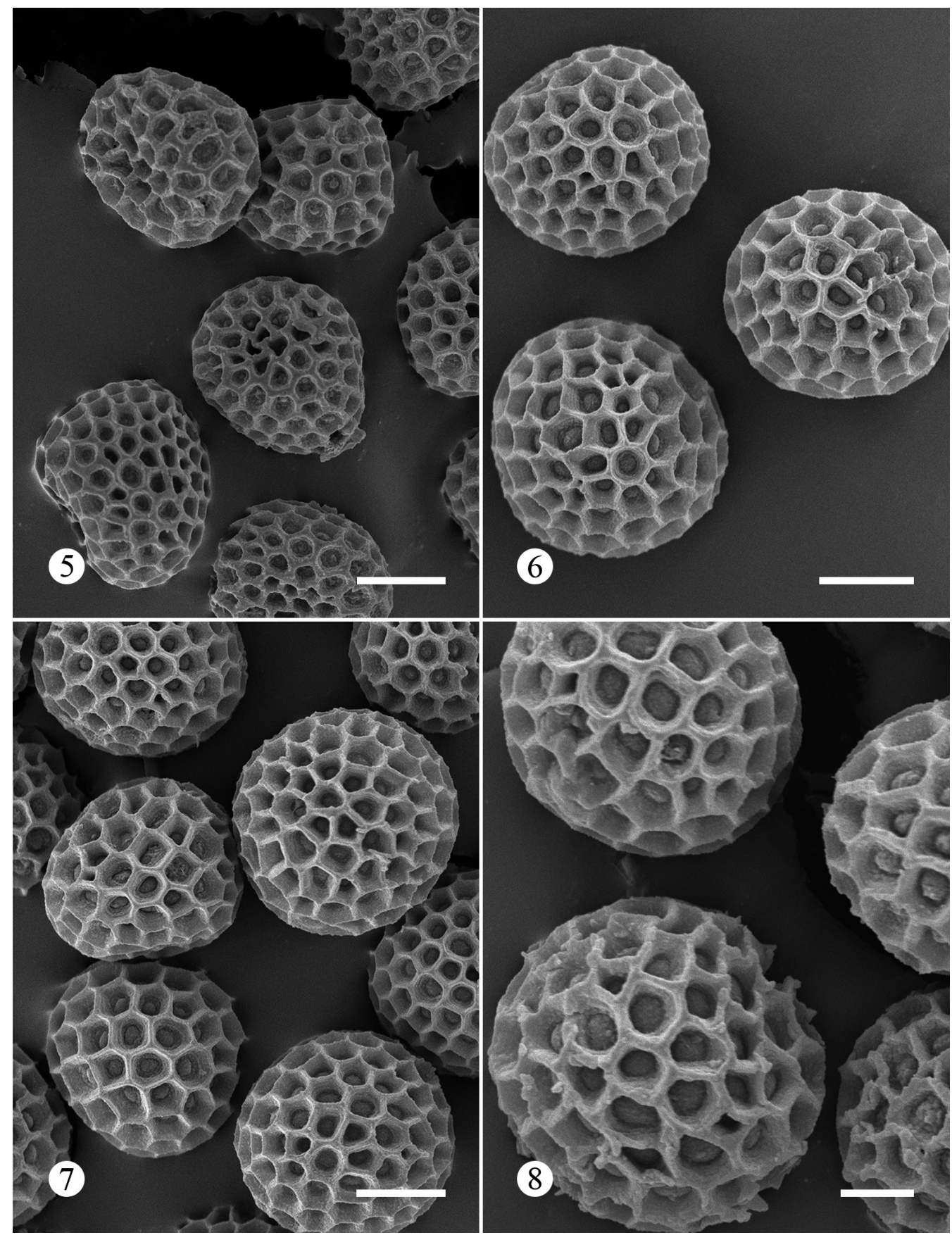

Fig. 5. Spores of Haradaea moenchiae-manticae on Moenchia erecta subsp. erecta (MA 205833) in SEM. Figs 6-8. Spores of H. moenchiae-manticae on Moenchia erecta subsp. octandra in SEM (6, 7 - MA 35045, 8 - MA-Funhist 17169). Scale bars $=5 \mu \mathrm{m}$ 


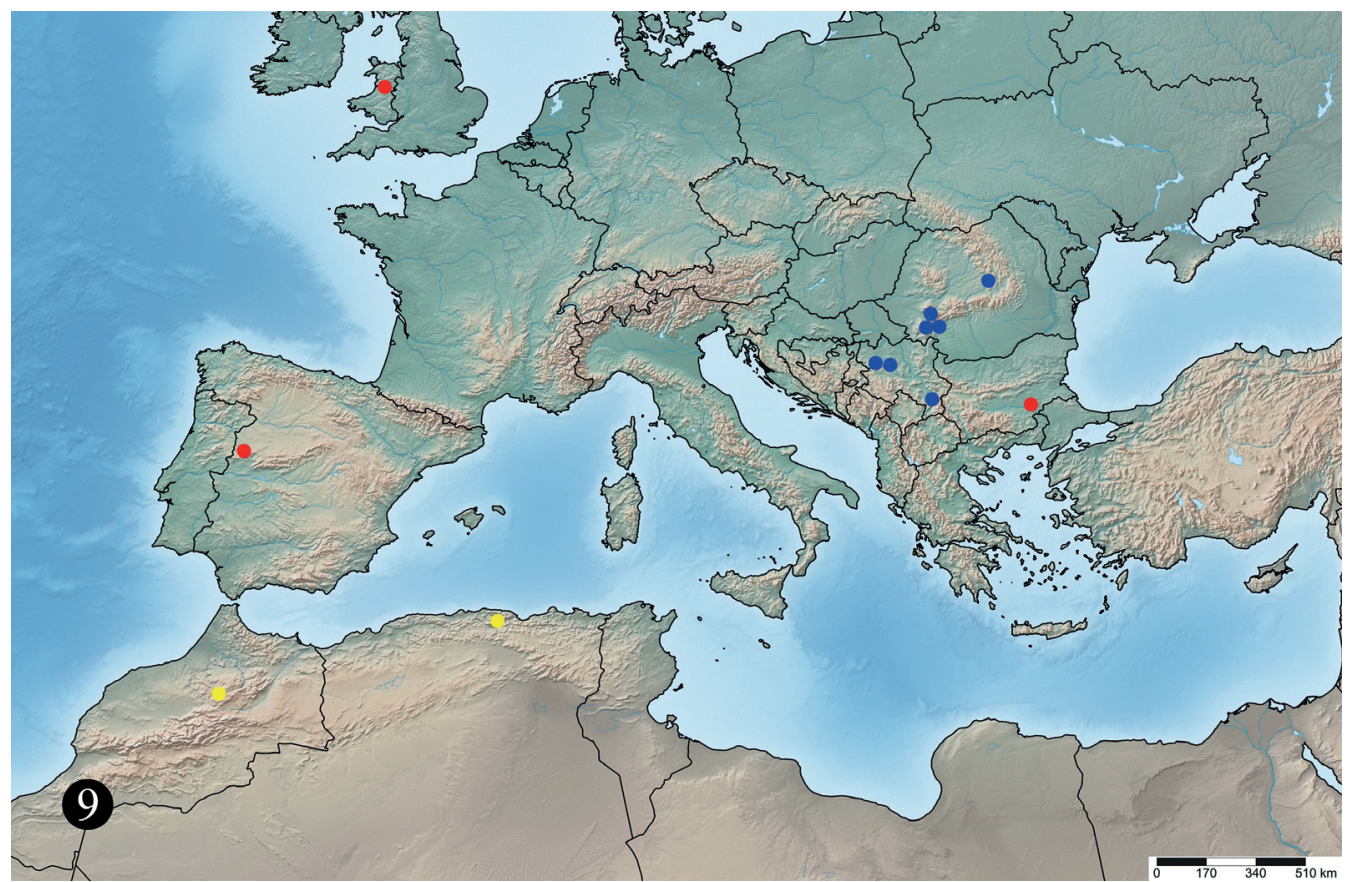

Fig. 9. Geographic distribution of Haradaea moenchiae-manticae (generated with SimpleMappr, Shorthouse 2010): blue circles - collections on Moenchia mantica subsp. manti$c a$, red circles - on $M$. erecta subsp. erecta, and yellow circles - on M. erecta subsp. octandra

Acknowledgements. This research received support (Grant no. ES-TAF-6618) from the SYNTHESYS Project http://www.synthesys.info/ which is financed by European Community Research Infrastructure Action under the FP7 "Capacities" Program at the Real Jardín Botánico (CSIC). The assistance of Prof. Maria T. Tellería, Dr Maria P. Martín, Dr Margarita Dueñas, Dr Yolanda Ruiz-León, and the staff of MA is kindly acknowledged.

\section{References}

Almaraz, T. 2002. Bases corológicas de Flora Micológica Ibérica Números 1766-1932. - In: F. Pando \& J.C. Hernández (eds). Cuadernos de Trabajo de Flora Micológica Ibérica. Vol. 17. Pp. 11-124. CSIC, Real Jardín Botánico, Madrid.

Denchev, C.M. 1997. Taxonomical studies on ovariicolous ustomycetes on Caryophyllaceae. I. Ustilago jehudana and U. moenchiae-manticae. - Mycoscience 38: 323-328.

Denchev, C.M. 2001. [Classis Ustomycetes (Ordines Tilletiales, Ustilaginales et Graphiolales)]. - In: V. Fakirova (ed.). Fungi Bulgariae 4: 1-286. Editio Academica "Prof. Marin Drinov" \& Editio Pensoft, Sofia. (In Bulgarian)

Denchev, C.M. 2006. Haradaea afromontana, comb. nov. (Microbotryaceae). - Mycologia Balcanica 3: 216. 
Denchev, C.M., Kakishima, M., Shin, H.D. \& Lee, S.K. 2006a. Notes on some Japanese smut fungi. III. Ustilago moehringiae. - Mycotaxon 98: 181-184.

Denchev, C.M., Moore, R.T. \& Shin, H.D. 2006b. A reappraisal of the genus Bauhinus (Microbotryaceae).Mycologia Balcanica 3: 71-75.

Denchev, C.M., Denchev, T.T., Spooner, B.M. \& Helfer, S. 2010. New records of smut fungi. 3. Mycotaxon 114: 225-230.

Lindtner, V. 1950. [Ustilaginales of Jugoslavia]. - Bulletin du Muséum d'Histoire Naturelle du Pays Serbe, Série B 3-4: 1-110. (In Serbian)

Maire, R. 1916. Schedae ad Mycothecam Boreali-Africanam. - Bulletin de la Société d'Histoire Naturelle de l'Afrique du Nord 7: 294-303.

Săvulescu, T. 1957. [Ustilaginales of the Romanian People's Republic]. Vol. 2. Editio Academiae Reipublicae Popularis Romanicae, Bucharest. (In Romanian)

Shorthouse, D.P. 2010. SimpleMappr, an online tool to produce publication-quality point maps. Available from: http://www.simplemappr.net (accessed 7 April 2017).

Vánky, K. 1985. Carpathian Ustilaginales. - Symbolae Botanicae Upsalienses 24(2): 1-309.

Vánky, K. 2011['2012']. Smut fungi of the world. APS Press, St. Paul, Minnesota, USA.

Vánky, K., Vánky, C. \& Denchev, C.M. 2011. Smut fungi in Africa - a checklist. - Mycologia Balcanica 8: $1-77$. 